\title{
A COMPOSIÇÃO DO CONSELHO DE ADMINISTRAÇÃO NA DETERMINAÇÃO DO CAPITAL INTELECTUAL
}

\author{
THE BOARD OF DIRECTORS COMPOSITION AS A DETERMINANT OF COMPANY'S \\ INTELLECTUAL CAPITAL
}

IVAN RAFAEL DEFAVERI

Mestre em Contabilidade pela Universidade Estadual do Oeste do Paraná (UNIOESTE) Professor do Departamento de Contabilidade da Universidade Estadual de Maringá (UEM) Orcid: https://orcid.org/0000-0002-7385-6948

E-mail: ivandefaveri@hotmail.com Avenida Colombo, 5790, Bloco C-23, Maringá - PR, CEP: 87030-121

\section{DELCI GRAPEGIA DAL VESCO}

Doutora em Contabilidade pela Universidade Regional de Blumenau (FURB) Professora do PPG em Contabilidade pela Universidade Estadual do Oeste do Paraná (UNIOESTE) Orcid: http://orcid.org/0000-0002-0818-3142

E-mail: delcigrape@gmail.com

Submissão: 25/06/2020. Revisão: 29/12/2020. Aceite: 24/05/2021. Publicação: 24/05/2021. DOI: http://dx.doi.org/10.22277/rgo.v14i2.5607

\section{RESUMO}

Este estudo teve como objetivo investigar a relação entre a construção de capital intelectual e a composição dos conselhos de administração, com enfoque, sobretudo, na constituição de interlocks entre empresas. Foram levantados dados da base Economatica (C e do sítio eletrônico da B3, sendo o capital intelectual mensurado por meio do método VAIC. Foi utilizado o software estatístico Stata ${ }^{\circledR}$, com aplicação da modelagem de Equações de Estimação Generalizadas (EEQ). Os resultados encontrados indicam que o tamanho do conselho de administração afeta positivamente a composição do capital intelectual. Já a independência do conselho mostrou relação negativa, quanto mais membros independentes houver no conselho, pior tende a ser o capital intelectual da companhia. A variável de interlock entre conselhos de administração não mostrou resultados estatisticamente válidos, de modo que não se pode afirmar que essa relação apresenta melhoras no capital intelectual. Desse modo, pôde-se evidenciar alguns dos elementos de composição dos conselhos de administração que afetam a composição do capital intelectual, de modo que as empresas possam utilizar tais resultados como referência na formação dos conselhos, de modo a buscar uma alocação de recursos mais eficiente para a construção de conhecimento nessas companhias.

Palavras-chave: Composição do conselho de administração. Interlock entre empresas. Capital intelectual.

Este é um artigo publicado em acesso aberto (Open Access) sob a licença Creative Commons Attribution, que permite uso, distribuição e reprodução em qualquer meio, sem restrições desde que o trabalho original seja corretamente citado. 


\begin{abstract}
This study aimed to investigate the relationship between the construction of intellectual capital and the establishment of interlocks between companies. Data were collected from the Economatica $\bigcirc$ database and the B3 website, and the intellectual capital was measured using the VAIC method. Stata ${ }^{\circledR}$ statistical software was use, with the application of Generalized Estimation Equation (GEE) modeling. The results found indicate that the size of the board of directors positively affects the composition of intellectual capital. The board's independence showed a negative relationship, the more independent members there are on the board, the worse the company's intellectual capital tends to be. The interlock variable between boards of directors did not show statistically valid results, so it cannot be said that this relationship shows improvements in intellectual capital. It is concluded that the participation of members external to the company, despite bringing experiences and know-how to the company, does not necessarily improve the creation and application of knowledge in them.
\end{abstract}

Keywords: Companies interlock. Intellectual capital. Boards of directors composition.

\title{
1 INTRODUÇÃo
}

O conselho de administração é um órgão que visa assumir a responsabilidade de tomar decisões em nome dos proprietários de uma organização (ANDRADE et al., 2009). Essa responsabilidade faz o conselho de administração se apresentar como um importante mecanismo para as funções de gestão e controle das organizações (DAL VESCO; BEUREN, 2016). Dessa forma, o conselho se torna um instrumento de criação de valor para a companhia. Essa criação de valor se dá por meio da capacidade de o conselho criar e controlar atributos, como conhecimento, informação, experiência, relações, rotinas e procedimentos, tanto no nível individual, por meio de delegação de funções, quanto a nível corporativo, recursos estes que se relacionam com a criação do capital intelectual nas organizações (BONTIS, 1998).

O conselho de administração atua nas organizações como um intermediador entre os acionistas e os administradores, de modo a exercer relevante papel na redução dos conflitos de agência (DAL VESCO; BEUREN, 2016). Tal papel leva diversos autores a destacarem a necessidade de independência do conselho de administração, ou seja, a sua formação por membros externos à companhia, que não sejam acionistas ou componham o quadro de executivos da mesma (VALADARES; LEAL, 2000; ROSSONI; MACHADO-DA-SILVA, 2010; MOURA; BEUREN, 2011; TERJESEN; COUTO; FRANCISCO, 2015).

Existe na literatura o consenso de que conselhos mais independentes tenham uma maior autonomia decisória e produzem melhores informações (MOURA; FRANZ; CUNHA, 2015). No entanto, Duchin, Matsusaka e Ozbas (2010) indicam que os efeitos positivos dessa autonomia só se refletem em resultado para a companhia quando o custo da informação for baixo, ou seja, conselheiros independentes tendem a proporcionar melhores resultados quando têm um acesso mais fácil as informações (CHEN; CHENG; WANG, 2015).

Um meio de facilitar o acesso de informações aos conselheiros é por meio dos interlocks entre empresas (DAL VESCO; BEUREN, 2016). Assim, um conselho de administração composto por membros externos provenientes de outras empresas, gerando esse interlock entre as companhias, gera um acesso livre às informações sobre as características de determinado ramo. Isso auxilia tanto na melhoria do assessoramento aos gestores da empresa 
que compõem o conselho, quanto agregando informações úteis para a gestão da sua própria organização de atuação (GALASKIEWICZ et al., 1985).

Por meio dessa interligação entre gestores de diversas empresas, ocorre o compartilhamento de conhecimentos, uma vez que a construção desse networking permite que o capital intelectual formado nas diversas companhias das quais os membros do conselho provêm, seja reunido e passe a compor o capital da empresa em questão (BEREZINETS; GARANINA; ILINA, 2016). Esse capital intelectual é composto por diversas dimensões que envolvem o desenvolvimento de habilidades dentro das companhias, havendo também diferentes taxinomias para a exploração dessas dimensões (RAMADAN et al., 2017).

Para esse estudo foi escolhida a taxonomia determinada por Youndt e Snell (2004), segundo o qual o capital intelectual é composto pelo capital humano (representado pelo conhecimento tácito dos membros da organização), o capital estrutural (representa o conhecimento difundo diretamente na estrutura da empresa, institucionalizado no meio, independente do capital humano que a compõe), do capital social (conhecimentos compartilhados entre os membros da organização) e o capital organizacional (conhecimento acumulado, institucionalizado na forma de sistemas, bancos de dados, rotinas, documentações, etc.).

Desse modo, a forma como o conselho de administração é composto, levando em conta a independência dos seus membros em relação à empresa e à sua experiencia e participação em outras organizações, gerando esse interlock, faz com que tais executivos compartilhem entre si o capital social trazido de suas companhias, permitindo o desenvolvimento do capital organizacional e humano, o que por sua vez também leva ao crescimento do capital estrutural da empresa (TERJESEN; COUTO; FRANCISCO, 2015; BEREZINETS; GARANINA; ILINA, 2016; DAL VESCO; BEUREN, 2016).

Essa busca por identificar a relação entre a composição do conselho de administração, o compartilhamento de informações e o desenvolvimento do capital intelectual de companhias já foi investigado por outros estudos, como o de Terjesen, Couto e Francisco (2015), que buscou identificar se a independência e o gênero dos membros do conselho podem afetar no desempenho da empresa. Outros estudos buscaram identificar se os interlocks entre CEOs de diferentes empresas na composição dos conselhos permite a criação de uma rede de relacionamentos que reflete na gestão das companhias (GALASKIEWICKZ et al., 1985; GULATI; WESTPHAL, 1999).

Existem ainda estudos focados na investigação de como os interlock entre empresas na composição dos conselhos de administração, associados à estrutura de propriedade (DAL VESCO; BEUREN, 2016) e ao capital social (ROSSONI; ARANHA; MENDES-DA-SILVA, 2017), podem afetar no desempenho das companhias. Os estudos de Berezinets, Garanina e Ilina (2016) e Nkundabanyanga (2016), por sua vez, investigaram como a composição dos conselhos de administração influenciam na criação e manutenção do capital intelectual, bem como o impacto que isso pode ter na própria empresa. A presente pesquisa avança e difere em relação aos dois estudos citados, uma vez que Berezinets, Garanina e Ilina (2016) realizaram uma pesquisa de escopo teórico, de modo a investigarem os precedentes na literatura que permitissem relacionar os elementos citados, sem avançar para um estudo empírico, no qual fossem testadas as relações encontradas. Já quanto ao estudo de Nkundabanyanga (2016), a principal diferença, que justifica a realização do estudo, consiste no método de investigação empírica, uma vez que na pesquisa supracitada utilizou-se de questionários, aplicados diretamente aos gestores e conselheiros de administração das empresas componentes da amostra. A presente pesquisa, por sua vez, buscou dados 
constantes das demonstrações contábeis de empresas listadas, de modo a obter os efeitos observáveis do relacionamento entre as variáveis, sem o viés de julgamento passível dos questionários autoaplicáveis.

Com base nos resultados de Berezinets, Garanina e Ilina (2016) e Nkundabanyanga (2016), a importância da execução desta pesquisa é reforçada pela relação já constatada entre a forma como o conselho de administração é composto e o desenvolvimento do capital intelectual nas empresas. A relevância e contribuição do estudo residem na necessidade de se identificar o comportamento dessas variáveis em empresas que operam no Brasil, de forma a se entender os elementos do conselho de administração que são determinantes à formação do capital intelectual. Com base nisto às empresas locais poderem embasar a escolha dos membros e os elementos componentes dos seus conselhos, podendo assim desenvolver de maneira mais efetiva o conhecimento na companhia, favorecendo assim a melhoria de desempenho empresarial e o desenvolvimento e econômico do país.

Com a finalidade de atender a esse propósito, foi elaborada como questão norteadora da pesquisa, qual a influência da composição do conselho de administração sobre a determinação do capital intelectual? Dada essa questão, o objetivo da pesquisa passa a ser verificar a influência da composição do conselho de administração na determinação do capital intelectual de empresas.

Para alcançar esse objetivo, o artigo é composto, além desta introdução, do referencial teórico, o qual busca identificar aspectos conceituais que permitam inferir sobre a relação entre a composição dos conselhos de administração, interlock entre empresas e a determinação do capital intelectual. Em sequência um capítulo voltado a determinação e apresentação dos aspectos metodológicos direcionadores do trabalho, a apresentação e discussão dos dados buscando a identificação e análise das relações propostas, e por fim as conclusões relativas aos resultados.

\section{REFERENCIAL TEÓRICO}

\subsection{CAPITAL INTELECTUAL}

Existem diferentes definições para a conceituação do capital intelectual, no entanto, a maioria delas converge para a ideia de esse capital corresponder aos ativos intangíveis que não estão listados nas demonstrações contábeis das empresas (OZKAN; CAKAN; KAYACAN, 2017). Esses ativos representam a soma dos conhecimentos da empresa, de modo a gerar vantagens competitivas (SUBRAMANIAM; YOUNDT, 2005). Tradicionalmente, a literatura reconhece três categorias de capital intelectual, sendo elas o capital humano, estrutural e de clientes (BONTIS, 1998).

O capital humano representa as habilidades dos empregados, o capital estrutural são as estruturas da empresa, como softwares, marcas e bancos de dados, e o capital de clientes representa o relacionamento da empresa com seus clientes (EDVINSSON; MALONE, 1998).

Mais especificamente, o capital humano pode ser entendido como o know-how construído na empresa por meio dos seus funcionários, ou seja, o conhecimento que se mantém mesmo quando da saída do funcionário da empresa, e que se encontra indefinidamente disponível para ser utilizado por todos os seus componentes (SUBRAMANIAM; YOUNDT, 2005; OZKAN; CAKAN; KAYACAN, 2017). O capital estrutural, por sua vez, representa os procedimentos contidos na organização capazes de dar suporte ao desenvolvimento intelectual de seus funcionários (BONTIS, 1998). O autor coloca ainda que mesmo que uma organização tenha um capital intelectual muito forte e desenvolvido, se não 
houver uma estrutura organizacional adequada esse capital não será capaz de ser refletido em melhor desempenho e na criação de valor.

Já o capital de clientes é entendido por Oliveira e Beuren (2003) como sendo a maneira como a empresa é vista por seus clientes, e como se relaciona com eles. Desse modo, os autores consideram uma representação desse capital o goodwill, uma vez que essa diferença entre o valor contábil e de mercado da empresa representa como ela é vista pelo mercado, ou seja, quanto maior o goodwill, melhor a imagem da empresa.

Assim, percebe-se que o capital intelectual não representa apenas aspectos subjetivos dentro das organizações, mas sim uma junção de fatores que envolvem investimentos, pesquisa e desenvolvimento de novas ações (LIMA; CARMONA, 2011). Essa materialidade do capital intelectual é refletida na criação de valor das companhias, uma vez que uma gestão adequada dos três fatores elencados está conectada com melhores resultados e com a valoração da empresa (DZENOPOLJAC; JANOSEVIC; BONTIS, 2016; LIU, 2017).

Visando uma maneira mais objetiva de medir como o capital intelectual das empresas cria valor a estas, Pulic (1998) desenvolveu o modelo conhecido como Vallue Added Intelectual Coefficiant $^{T M}$ (VAIC $^{\mathrm{TM}}$ ), ou Coeficiente Intelectual de Valor Agregado. Esse modelo busca medir se os recursos intelectuais das empresas estão sendo utilizados de maneira eficiente ou não, com fins de criar valor agregado (OZKAN et al., 2017). Pulic (1998) desenvolveu esse modelo por considerar as medidas utilizadas até então para a medição do capital intelectual demasiado subjetivas, de modo a pretender criar uma métrica capaz de mensurar esse capital e sua utilidade para as empresas em termos financeiros.

A ideia de capital intelectual de Pulic (1998) se divide em dois grupos principais, sendo eles os recursos físicos, ou recursos financeiros, e o potencial intelectual, que é a capacidade de os empregados gerarem valor para a empresa (CARVALHO et al., 2017). Para medir esses dois componentes, Pulic (1998) desenvolveu a fórmula do VAIC ${ }^{\text {TM }}$, que inclui o valor agregado (VA), a eficiência do capital aplicado (CEE), a eficiência do capital humano (HCE) e a eficiência do capital estrutural (SCE).

Kochen e Brandt (2017) elencam as etapas para a construção do VAIC como segue:

a) $V A=$ Valor Adicionado gerado pela empresa. Valor Adicionado Bruto informado na DVA (Demonstração de Valor Adicionado);

b) $\mathrm{GP}=$ Gastos com pessoal. Informado na DVA das empresas;

c) $\mathrm{CE}=$ Capital empregado. Valor total do Patrimônio Líquido;

d) $\mathrm{SC}=\mathrm{VA}-\mathrm{GP}$ (proxy para o capital estrutural);

e) $\mathrm{HCE}=\mathrm{VA} / \mathrm{GP}$ (indicador de eficiência do capital humano);

f) $\mathrm{CEE}=\mathrm{VA} / \mathrm{CE}$ (indicador da eficiência do capital investido);

g) $\mathrm{SCE}=\mathrm{SC} / \mathrm{VA}$ (indicador estrutural da eficiência de capital);

h) $\mathrm{VAIC}=\mathrm{HCE}+\mathrm{CEE}+\mathrm{SCE}$

Seguindo essa fórmula, tem-se uma previsão da existência das três dimensões do capital intelectual levantadas por Bontis (1998), mensuradas a partir de contas contábeis específicas, que indicam a aplicação de recursos ou o desempenho proporcionado à empresa por essas dimensões intelectuais inerentes à organização e aos seus componentes. Dada a característica do cálculo do VAIC, nota-se que o valor resultante da aplicação da fórmula em uma empresa é um reflexo da gestão desta. Em empresas de capital aberto, as práticas e principais diretrizes da gestão são formuladas e/ou controladas pelo conselho de administração (ANDRADE et al., 2009). Desse modo, na sequência, iremos no aprofundar um pouco mais na forma como o conselho de administração é constituído, bem como discutir de 
que modo a sua composição pode se relacionar com a construção do capital intelectual nas companhias.

\subsection{COMPOSIÇÃO DO CONSELHO DE ADMINISTRAÇÃO}

O conselho de administração é um órgão colegiado dentro das empresas que tem como intuito coordenar e liderar o processo decisório de uma companhia sem, contudo, interferir diretamente nas operações cotidianas desta, bem como nos deveres e decisões dos executivos sêniores da empresa (ZAHARA; PEARCE, 1989). Assim, o conselho se estabelece com o objetivo de tomar decisões em nome dos proprietários da empresa, de modo a evitar alterações e desvios nos padrões de controle e propriedade das companhias (ANDRADE et al., 2009; LEAL; OLIVEIRA, 2002).

Adams, Hermalin e Weisbach (2010) revisaram a literatura em busca de definições que respondam quais as funções de um conselho de administração. Os autores identificaram como principais funções a de formular estratégias, indicar a direção a ser seguida pela firma, politicas corporativas a serem aplicadas, além de fornecer e monitorar a aplicação de recursos pelos executivos da empresa. Essa última função se mostra particularmente relevante a esta pesquisa, uma vez que, ao se levar em conta a natureza do modelo VAIC, a definição e monitoramento das diretrizes para aplicação de recursos na empresa pode ocasionar alterações nos resultados inerentes ao capital intelectual.

Como, em geral, uma das principais funções do conselho é avaliar e fiscalizar os executivos da empresa, fica implícita a necessidade de o conselho ser composto por membros externos à empresa, o que é chamado de independência do conselho (KLEIN, 2002). Essa necessidade está relacionada com a teoria da agência. Essa teoria diz que os interesses dos agentes tendem a ser diferentes, ou seja, os objetivos dos executivos podem não ser os mesmos dos proprietários da empresa, havendo assim distorções nos processos (ROCHA et al., 2012).

Dessa forma, Adams, Hermalin e Weisbach (2010) consideram a independência do conselho como ferramenta para a redução dos problemas oriundos da teoria da agência. Essa independência permite ao conselho direcionar as ações da empresa sem que estas pendam para uma das partes interessadas, de modo a permitir maior acuracidade nas mesmas. Com relação ao capital intelectual, um conselho mais independente, de acordo com Taliyang e Jusop (2011), tende a proporcionar uma menor distorção nas decisões e nos dados evidenciados, proporcionando, assim, melhores resultados relativos ao capital intelectual, uma vez que o conselho independente busca frear o ímpeto dos executivos de direcionarem as decisões a seu favor. Desse modo, se espera uma relação significativa e positiva entre a independência do conselho de administração e o capital intelectual evidenciado.

Outro fator elencado pela literatura diz respeito ao tamanho do conselho de administração. Alves, Couto e Francisco (2015) colocam que trabalhos mais antigos indicam para o fato de conselhos menores serem mais eficientes para a tomada de decisões, além de apresentarem um custo menor para a informação. No entanto, os autores também indicam que evidências mais recentes apontam que conselhos maiores, sobretudo no contexto de empresas mais complexas, tendem a apresentar melhores resultados. Esse resultado também é apresentado por Dani et al. (2017), os quais encontraram que maiores conselhos tendem a apresentar maiores resultados, uma vez que, de acordo com os resultados dos testes realizados, à medida que o tamanho do conselho aumenta, o desempenho também aumenta. Oliveira et al. (2016) argumentam que o tamanho mínimo ideal para composição do conselho de administração é de cinco membros, e que se recomenda não haver mais do que nove. 
Hidalgo, García-Meca e Martínez (2011) identificaram que conselhos maiores apresentam melhores resultados no tocante à evidenciação de intangíveis e do capital intelectual. De acordo com os resultados, conselhos maiores, até um limite de 15 membros, possibilitam uma fiscalização mais eficiente, uma comunicação mais abrangente, e um menor efeito do viés de opinião dos conselheiros, de forma a proporcionar melhores resultados relativos ao capital intelectual. Contudo, conselhos muito maiores tendem a ter muito ruído de comunicação e um custo elevado de manutenção, em contrapartida a um resultado igual ou inferior. No entanto, ao se levar em conta a característica dos conselhos brasileiros, que possuem em geral até 10 membros, se espera que o tamanho do conselho de administração afete de forma significativa e positiva a construção do capital intelectual das companhias estudadas.

Uma terceira característica costumeiramente elencada como de importância para a análise da composição do conselho de administração é a dualidade do CEO. Isso implica em se verificar se o presidente ou diretor responsável pela empresa preside também o conselho de administração. Oliveira et al. (2016) consideram que quando ambos os cargos são exercidos por pessoas diferentes, o conselho tende a ter maior autonomia nas suas decisões. Adams, Hermalin e Weisbach (2010) consideram que a dualidade do CEO não necessariamente representa um maior ou menor desempenho, mas sim um maior controle e poder decisório por parte do gestor.

Alves, Couto e Francisco (2015) consideram que essa condição tem reflexo na geração de informações pela empresa, dado o fato de o CEO não presidir o conselho de administração possibilita maior transparência e acurácia nas informações. No contexto da presente pesquisa, se considera que, quando o CEO preside o conselho de administração, ele tem a tendência a direcionar as decisões e a divulgação de informações de modo a criar um resultado mais favorável a sí próprio. Desse modo, gastos e investimentos podem ser suprimidos das demonstrações contábeis da empresa, proporcionando um melhor resultado contábil, mas afetando negativamente no capital intelectual evidenciado. Dado esse fato, se espera uma relação significativa e positiva entre a dualidade do CEO e a evidenciação do capital intelectual, ou seja, em organizações em que o CEO não preside o conselho de administração, espera-se resultados melhores em relação ao capital intelectual.

Uma outra característica considerada de relevância na composição dos conselhos de administração é o interlock de membros entre empresas. Esse interlock representa a participação de CEOs de uma empresa no conselho de administração de outras empresas, compartilhando assim suas experiências e conhecimentos (DAL VESCO; BEUREN, 2016). Desse modo, se espera uma melhora no processo decisório, que fica mais apurado e embasado. Fores (2013) indica que um interlock entre empresas é formado quando uma pessoa, participante de uma empresa, seja como diretor ou como membro do conselho de administração, participa simultaneamente do conselho de uma empresa externa. Galaskiewicz et al. (1985) consideram que essa modalidade de configuração dos conselhos de administração auxilia no combate às incertezas estratégicas, protegendo os recursos ambientais, além de ser um meio de aumentar o prestígio tanto da organização anfitriã, quanto da cedente, devido a interação dos gestores de empresas renomadas.

Chu e Davis (2016), por sua vez, consideram que os interlocks permitem o compartilhamento de práticas de governança, difundido práticas de sucesso de determinadas empresas com aquelas em que seus diretores participam do conselho de administração. Essa ideia entra em consonância com Lazzarini (2007), segundo o qual, a conexão entre os membros de diferentes empresas no conselho de administração permite à empresa anfitriã 
usufruir dos conhecimentos desses para melhorar suas próprias atividades. Shropshire (2010) indica que a criação dos interlocks permite a difusão de ideias, informações e know-how, caracterizando-se como um canal de comunicação desses atributos entre as empresas constituintes desse interlock.

Com relação à presente pesquisa, se espera uma relação significativa e positiva entre os interlocks e o capital intelectual. Essa relação esperada se justifica pela tese de que os conselheiros externos membros da gestão ou de conselhos de outras empresas, trazem consigo uma maior gama de conhecimentos e habilidades, as quais, quando aplicadas na organização, proporcionam o desenvolvimento do capital intelectual em suas três dimensões.

Com o intuito de determinar qual a relação entre a forma como o conselho de administração é composto e o capital intelectual evidenciado, foi conduzida uma pesquisa empírica, cujas diretrizes e métodos são apresentadas na seção a seguir.

\section{METODOLOGIA}

Essa pesquisa é uma pesquisa de abordagem quantitativa, tendo como objetivos de pesquisa ser um estudo descritivo, ou seja, busca descrever o relacionamento da composição do conselho de administração de empresas na constituição do capital intelectual destas. A pesquisa se caracteriza ainda como uma pesquisa documental, por utilizar dados secundários, coletados a partir da base de dados Economatica (C. A análise da relação entre as variáveis se deu por meio do uso de modelo econométrico, de modo a verificar a existência de relações positivas (ou não) entre as variáveis em estudo. O modelo econométrico em questão é representado pela equação a seguir:

Onde:

$$
C l_{i}=\alpha_{i}+b_{1} \text { TamCon }_{i t}+b_{1} \text { Interlock }_{i}+b_{2} \text { Indep }_{i}+b_{3} \text { DuoCEO }_{i+} b_{4} \operatorname{TAM}_{i+} \varepsilon_{i t}
$$

$\mathrm{Cl}=$ Capital Intelectual;

TamCon = Quantidade absoluta de membros do conselho

Interlock = Participação em dois ou mais conselhos de administração;

Indep = Proporção de membros independentes no conselho;

DuoCEO = Presidente da empresa preside o conselho de administração;

TAM = Tamanho da empresa.

As variáveis que compõem o modelo foram escolhidas de acordo com os relacionamentos esperados das mesmas, de acordo com o descrito na seção 2 deste estudo. A variável dependente do modelo é o capital intelectual apresentado pelas empresas, e as variáveis independentes, as quais se espera identificar o relacionamento com a dependente, são as variáveis relativas à composição do conselho de administração. As informações pertinentes à composição das variáveis estão descritas no Quadro 1.

Em adição as variáveis independentes, cujo relacionamento com a variável dependente está descrito na base teórica deste estudo, foi adicionada a variável de controle relativa ao tamanho da empresa. Essa variável foi considerada útil e de relevância para esta pesquisa, uma vez que, o porte das empresas pode afetar as práticas de gestão executadas, tanto por executivos quanto pelo conselho de administração, de modo à sua inclusão no modelo teórico buscar identificar as empresas de maior porte possuem um comportamento distinto daquelas de porte inferior no que tange à criação e manutenção do capital intelectual. 
A composição do conselho de administração na determinação do capital intelectual

Quadro 1 - Construto do modelo

\begin{tabular}{|l|l|l|l|}
\hline Variável & \multicolumn{1}{|c|}{ Tipo } & \multicolumn{1}{|c|}{ Indicador } & \multicolumn{1}{c|}{ Autor base } \\
\hline $\mathrm{Cl}$ & Dependente & VAIC = HCE+CEE+SCE & Pulic (1998); Carvalho et al. (2017) \\
\hline TamCon & Independente & Número de membros & Hidalgo, García-Meca e Martínez (2011) \\
\hline Interlock & Independente & $\begin{array}{l}\text { Proporção de membros que } \\
\text { participem da gestão de outras } \\
\text { empresas }\end{array}$ & Al-Musali e Ismail (2012) \\
\hline Indep & Independente & $\begin{array}{l}\text { Proporção de membros que não } \\
\text { façam parte da empresa }\end{array}$ & Taliyang e Jusop (2011) \\
\hline DuoCEO & Independente & $\begin{array}{l}\text { 1 para CEO que preside o conselho } \\
\text { de administração e 0 para CEO que } \\
\text { não preside }\end{array}$ & Terjesen, Couto e Francisco (2015) \\
\hline TAM & Controle & Log natural do ativo da empresa & Hidalgo, García-Meca e Martínez (2011) \\
\hline
\end{tabular}

Fonte: elaborado pelos autores (2020).

Os dados referentes à composição do VAIC, bem como o valor do ativo das empresas, foram extraídos das demonstrações contábeis divulgadas por meio da base Economatica (C), enquanto as informações sobre o conselho de administração das empresas foram obtidas por meio dos formulários de referência disponíveis no site da B3. Foram excluídas da amostra inicial as empresas do setor financeiro, devido às características inerentes as estas empresas que as distinguem das demais, o que poderia causar alterações nos resultados.

Dentro da plataforma Economatica (C), foram utilizados filtros para a seleção das empresas, com dados de Valor Adicionado Bruto, referente à Demonstração de Valor Agregado, que possuíssem uma conta analítica na DVA para os gastos e despesa com pessoal, bem como o valor total do Patrimônio Líquido e do Ativo. Com exceção do Ativo, utilizado como variável de controle, os demais dados são necessários ao cálculo das proxys e indicadores componentes do VAIC. Foi utilizado o período de coleta dos dados entre 2014 e 2018, de modo que empresas que tenham aberto o capital após o ano de 2014 foram excluídas automaticamente da amostra.

Após a seleção das empresas pelos critérios descritos, foram buscadas informações sobre a composição do conselho de administração de cada empresa ao longo do período, tanto nos formulários de referência publicados no sítio eletrônico da B3, quanto diretamente nos sítios eletrônicos das empresas, excluindo-se da amostra aquelas que não possuíssem qualquer uma das informações necessárias às variáveis do estudo em algum dos anos do recorte temporal. Desse modo, se chegou a um total de 23 empresas, totalizando 115 observações. Foi optado pela não segregação das empresas pelo setor, ou mesmo do uso de uma variável de controle para tal, uma vez que, das 23 empresas, 17 eram do setor de Utilidade Pública ou de Combustíveis, de modo que se considerou que a pouca diversidade em relação ao setor não representa interferência significativa nos resultados.

Os dados foram tabulados com o uso do software MSExcel (C), e o modelo econométrico foi operacionalizado por meio do software $\operatorname{Stata}^{\circledR}$, na versão 14.0. No primeiro momento, foi feita a estimação do modelo, para se estabelecer os pressupostos econométricos. Por meio do teste de Shapiro-Wilk, demonstrado na Tabela 1, foi encontrado que os dados apresentam uma distribuição não-normal dos resíduos, com exceção da variável TamCon. Por sua vez, os dados não apresentaram problemas de multicolinearidade, evidenciado pela média do VIF (Variance Inflation Factor), de 1,30, sendo, portanto, menor que 10, e suficiente para descartar a hipótese de multicolinearidade. O teste de Breusch-Pagan e o teste de White, por 
sua vez, indicam a existência de erros heterocedásticos na amostra, uma vez que ambos tiveram $\mathrm{p}$-valor significativo $(0,0000$ e 3,7e-06, respectivamente).

Tabela 1 - Teste Shapiro-Wilk

\begin{tabular}{|c|c|c|c|}
\hline Variável & Observações & W & p-valor \\
\hline VAIC & 115 & 0,7058 & 0,00000 \\
\hline TamCon & 115 & 0,99356 & 0,87456 \\
\hline Indep & 115 & 0,94366 & 0,00011 \\
\hline Interlock & 115 & 0,94725 & 0,00019 \\
\hline DuoCEO & 115 & 0,97058 & 0,01236 \\
\hline TAM & 115 & 0,93106 & 0,00002 \\
\hline
\end{tabular}

Fonte: dados da Pesquisa (2020).

Dadas essas características dos dados amostrais, optou-se pela utilização de modelagem econométrica pautada em Equações de Estimação Generalizadas. De acordo com Agranonik (2009), esse método é uma extensão do método de Mínimos Quadrados Generalizados (MQG), contudo, diferente deste outro método, as EEG não se pautam no pressuposta da existência de distribuição normal dos dados, sendo, portanto, adequadas para uso com dados de distribuição não-normal, como os da presente pesquisa. Agranonik (2009) também indica que esse método é adequado para uso com variáveis correlacionadas, como no caso da presente pesquisa, em que os dados são dispostos na forma de painel (dados de várias empresas ao longo de vários períodos de tempo). Por fim, a autora indica para o fato de as EEG serem ideais para se verificar a predição de variáveis para um grupo específico de observações, condição que se aplica à presente pesquisa, que observa especificamente empresas listadas na B3.

Tendo-se definidos os parâmetros da pesquisa, o próximo capítulo traz os resultados dos testes estáticos, bem como a análise e discussão dos resultados pertinentes à pesquisa.

\section{ANÁLISE E DISCUSSÃO DOS RESULTADOS}

Com base nos procedimentos expostos no capítulo anterior, os dados foram rodados no software Stata ${ }^{\circledR}$ com o objetivo de verificar a existência de relação entre os interlock em conselhos de administração e a composição do capital intelectual de empresas listas na B3. Os dados obtidos a partir do modelo econométrico pelo método de Equações de Estimação Generalizadas podem ser verificados na Tabela 2.

Tabela 2 - Resultados do Modelo Econométrico

\begin{tabular}{|c|c|c|c|}
\hline VAIC & Coef & Erro Pad. & $p$-valor \\
\hline TamCon & 0,2817282 & 0,125452 & $0,025^{* *}$ \\
\hline Indep & $-2,5962360$ & 1,1125600 & $0,020 * *$ \\
\hline Interlock & 0,6681574 & 0,7884546 & 0,397 \\
\hline DuoCEO & 0,7850375 & 0,4846736 & 0,105 \\
\hline TAM & $-0,2216953$ & 0,2491322 & 0,374 \\
\hline Const & 3,1640230 & 1,9830680 & 0,111 \\
\hline
\end{tabular}

\begin{tabular}{l} 
Sig Modelo $0,0571^{*}$ \\
\hline Fonte: dados da Pesquisa (2020). \\
$*=$ Significativo a $10 \% ; * *=$ Significativo a $5 \% ; * * *=$ Significativo a $1 \%$.
\end{tabular}

A partir da Tabela 2, podemos verificar os relacionamentos entre as variáveis preditivas do modelo com a variável VAIC. Os resultados indicam para a existência de relacionamento 
entre o número de membros do conselho e para a existência de membros independentes no conselho com a constituição do capital intelectual. O fato de apenas essas duas variáveis apresentarem resultados significativos estatisticamente, indica que o conselho de administração pode atuar como um determinante da construção do capital intelectual das empresas, mas essa influência não é abrangente, de modo a se supor a existência de outros elementos dentro das empresas que pode afetar essa determinação, e que não estão contidos nesse modelo. De modo a compreender melhor essa relação, discutiremos a seguir as possíveis causas das relações encontradas, a luz da literatura existente.

Entre as variáveis que mostraram uma relação estatisticamente válida com o capital intelectual, está o tamanho do conselho de administração, estando de acordo com o esperado com base na literatura. De acordo com os resultados, a inserção de um membro em um conselho pode ocasionar um aumento de até $28 \%$ no capital intelectual evidenciado, de modo que conselhos maiores tendem a proporcionar maior evolução do capital. Esse resultado se assemelha aos resultados de Dani et al. (2017), indicando que um conselho de administração maior traz resultados superiores para a empresa. Esses resultados podem se dar, segundo os autores, pela melhor captação de recursos, contribuições de competências, experiências e conhecimentos. Já segundo Hidalgo, García-Meca e Martinez (2011), a causa para essa variável se apresentar como válida pode ser a maior diversidade de ideias provenientes de um conselho maior, sem a deturpação de decisões devido a julgamentos pessoais. Os autores destacam que conselhos muito grandes podem ter problemas relativos à congruência de ideias e à comunicação, contudo, citam conselhos de mais de 15 pessoas, o que não é uma realidade no Brasil, uma vez que, em geral, a maioria dos conselhos possui números inferiores a este de conselheiros.

A outra relação estatisticamente válida foi a independência do conselho. Tal relação foi considerada válida no presente estudo, resultado semelhante ao de Dani et al. (2017) e de As-Musali e Ismail (2012), pois esses autores também encontraram uma relação estatisticamente negativa, ou seja, indicando que um aumente no número de conselheiros independentes reduz o capital intelectual. Esse resultado contradiz a doutrina presente na maioria dos estudos sobre governança corporativa, fato que pode ser explicado por fatores relacionado à escolha dos conselheiros independentes, de modo que a hipótese levantada com base na literatura não se confirmou, devido ao sinal contrário ao esperado.

Segundo As-Musali e Ismail (2012), a nomeação de conselheiros independentes não necessariamente trará pessoas verdadeiramente independentes para o conselho, uma vez que possam ser escolhidas pessoas com alguma relação, seja com a empresa, seja com os diretores, mesmo que sem participação no quadro de diretores ou acionistas. Isso faz, segundo os autores, que esses conselheiros independentes atuem de maneira a seguir as decisões do CEO das empresas, sem adicionar o componente de independência. Outra justificativa que Al-Musali e Ismail (2012) dão para esse fato, é que os auditores independentes, por mais que possam ser especialistas na área de atuação de determinada empresa, podem não conhecer tão bem os características especificas do funcionamento de cada empresa. Isso faz com que sua atuação possa gerar resultados negativos na evolução do capital intelectual, uma vez que buscam implementar métodos e ideias que funcionaram em outras empresas, mas que podem afetar na estrutura e nos conhecimentos institucionalizados dentro da companhia.

Por sua vez, o modelo não demonstrou a existência de uma relação estatisticamente válida entre os interlocks e o capital intelectual. Tais resultados demonstram que o interlock não se relaciona diretamente ao capital intelectual, quando este é mensurado por meio do 
VAIC. Isso pode demonstrar que a proporção de conselheiros interlocks não favorece na agregação de valor intelectual para a companhia. Como a pesquisa se utilizou da proporção dos membros interlocks em relação ao total de membros, os resultados indicam que haver mais ou menos membros que participam de outros conselhos de administração não traz resultados superiores para a organização.

Tais resultados corroboram ainda com Al-Musali e Ismail (2012), os quais também não encontraram relação entre o VAIC e a proporção do interlock no conselho de administração. A justificativa dos autores para esses resultados, a qual se considera válida também para 0 presente estudo, é de que o conselheiro interlock, por mais que consiga transmitir suas experiências e conhecimentos para o conselho, tem certa dificuldade em conhecer profundamente cada empresa da qual ele é conselheiro, de modo que, com pouca profundidade nos assuntos da companhia, não consiga aplicar esses conhecimentos de forma tão ampla, de forma a não trazer resultados positivos expressivos para a companhia no concernente a evolução do capital intelectual. Deve-se levar em conta, no entanto, que AlMusali e Ismail (2012) realizaram seu estudo em empresas de segmento financeiro, as quais foram excluídas da amostra do presente estudo, de modo que a natureza dos seus resultados pode ser distinta.

Esse resultado está em linha também com Blanco-Alcántara, Díez-Esteban e RomeroMerino (2019), os quais avaliaram a existência de interlocks com relação ao capital intelectual das empresas, com o índice de market-to-book como proxy para o capital intelectual. Os autores, assim como na presente pesquisa, encontraram um resultado que não permitiu corroborar a hipótese levantada de que o interlock entre membros de diferentes empresas proporciona aumento no capital intelectual. Como possíveis justificativas levantadas pelos autores, estão a possibilidade de a adição de conhecimentos provenientes de outras empresas não afetarem os resultados da empresa como um todo, mas sim, terem um impacto mais direcionado em setores específicos, afetando muito mais a eficiência interna destes, do que na eficácia global da empresa. Outra razão, que também se considera válida para o presente, é de o impacto do interlock só poder ser captado com condições e variáveis específicas, de modo que a confrontação direta dessa rede de relacionamentos entre empresas, adicionada a outros componentes do conselho de administração, não apresentar força estatística suficiente para determinar o capital intelectual das empresas.

As duas outras variáveis preditivas do modelo não apresentaram resultados estatisticamente significativos para a relação entre elas e o capital intelectual. A dualidade do CEO, ou seja, se o presidente da empresa também preside o conselho de administração, não mostrou relação com o capital intelectual, indicando que o acúmulo de funções não interfere na forma como os recursos são aplicados de modo a agregar valor ao capital intelectual da empresa. Esse resultado corrobora com os resultados de Dani et al. (2017), que também não conseguiram encontrar uma relação significativa entre a dualidade do CEO e o capital intelectual das empresas.

Esse resultado indica que não é possível validar a hipótese levantada a respeito dele. Como principais causas para isto, pode-se supor que havendo a atuação de um conselho de administração formado por um número significativo de membros, conforme o resultado da variável TamCon, a atuação CEO como presidente do conselho de administração não afeta acusa distorções significativas na aplicação de recursos, uma vez que essa distorção é mitigada pela atuação dos demais membros do conselho.

Por fim, não se conseguiu encontrar resultado estatisticamente significativo entre o tamanho das empresas, medido pelo log natural do ativo das companhias, e o capital 
A composição do conselho de administração na determinação do capital intelectual

intelectual, indicando que empresas maiores não necessariamente apresentam um melhor acúmulo de capital intelectual do que empresas menores, sendo essa característica condicionada a outros fatores.

Dessa forma, após serem evidenciados os resultados econométricos, bem como após ter sido feita a comparação dos resultados do presente estudo com resultados de outros estudos semelhantes, o próximo passo a ser tomado são as conclusões e considerações finais sobre os resultados apresentados, constantes da próxima sessão.

\section{CONSIDERAÇÕES FINAIS}

Tendo como tema central a constituição do capital intelectual das empresas, esse trabalho se propôs a investigar a relação entre a composição do conselho de administração e a constituição do capital intelectual das empresas.

Usando-se como métrica para a constituição do capital intelectual a variável VAIC, proposta por Pulic (2008), a qual visa medir o capital intelectual de acordo com a aplicação de recursos financeiros relacionados a ele na empresa, foi utilizado um modelo de Equações de Estimação Generalizadas para se medir as relações propostas.

Os resultados do modelo estatístico aplicado sugerem a existência de uma tênue relação entre a composição do conselho e o capital intelectual, uma vez que algumas das variáveis não apresentaram significância estatística para esse relacionamento. Essa influência da composição do conselho se dá sobretudo em relação ao fato de conselhos maiores apresentarem tendência a obter melhores resultados na aplicação dos recursos para o capital intelectual, de modo a indicar que empresas com mais membros tendem a ter um desempenho superior nesse campo.

Um resultado que contradisse o esperado em relação às hipóteses levantadas de acordo com a literatura diz respeito a independência do conselho. Seguindo a linha de outros estudos, que também divergiram com relação a essa relação, os resultados indicam que é mais vantajoso para a empresa manter um equilíbrio entre membros internos e independentes no conselho de administração, uma vez que conselhos com maior proporção de membros independentes apresentaram tendência a piores resultados com relação à constituição do capital intelectual.

O fato de variáveis como o interlock entre membros de diferentes companhias, ou o próprio tamanho da empresa não se apresentarem significativas, indica a possibilidade de haver outras variáveis capazes de interferirem nessa relação. Seria relevante uma investigação mais aprofundada sobre a literatura, com vistas a identificar quais variáveis independentes ou de controle poderiam ser aplicadas ao modelo, de modo a buscar uma compreensão mais aprofundada dessa relação. Cabe ressaltar que não existem muitos estudos que abordam a influência entre interlocks e capital intelectual, inclusive com a métrica utilizada para a mensuração deste capital usada no presente estudo. Desse modo, tais resultados indicam a necessidade de maior investigação teórica e de mais evidências empíricas para a definição de uma relação esperada mais apropriada em estudos futuros.

O estudo possui algumas limitações, as quais podem afetar os resultados encontrados. Entre essas limitações, está a impossibilidade de generalizar os dados, uma vez que, como a amostra foi composta por apenas 23 companhias, é presumível que os resultados não representem a totalidade das empresas listadas na bolsa de valores brasileira. $\mathrm{O}$ fato de os dados se limitarem a um recorte temporal de cinco anos também surge como uma limitação, 
pois modificações mais lentas na estrutura das empresas, ocasionadas pelas diversas trocas de conselheiros, podem não ter sido captadas.

Como principais implicações deste estudo, tem-se, no aspecto teórico, a adição de resultados empíricos a uma temática que ainda carece de mais fontes de dados, de modo a apoiar e direcionar a elaboração de estudos futuros sobre o tema. Esses resultados contribuem ainda ao adicionar elementos contrários ao entendimento estabelecido sobre algumas das variáveis, de modo a abrirem espaço para uma análise mais profunda dessas relações, testando novas teorias capazes de explicar os motivos dos resultados adversos. Já como contribuição prática que o estudo traz, está a definição de quais os elementos do conselho de administração podem afetar a construção do capital intelectual das empresas. Desse modo, empresas de capital aberto podem ter um norte com relação a estrutura mais adequada a ser adotada na composição do conselho, de modo a essa estrutura possibilitar resultados melhores no tocante ao capital intelectual. Em outras palavras, uma empresa que tenha como objetivo desenvolver o seu capital intelectual, pode utilizar o presente estudo como apoio na definição da composição do seu conselho de administração.

Por fim, sugere-se como estudos futuros a avaliação de tal relação em diferentes contextos, utilizando-se para isso de outras métricas para mensuração do capital intelectual que não as utilizadas nesse estudo. Também se sugere a realização de estudo do tipo levantamento de dados, ou mesmo estudos qualitativos, utilizando-se de entrevistas com gestores, CEOs e membros de conselho de administração, buscando sobretudo membros independentes e que realizem interlock. Nessas entrevistas, pode-se avaliar a percepção dos próprios membros de conselho sobre os elementos de composição deste, sobre as diferentes dimensões do capital intelectual e sobre como estes se relacionam. Outra sugestão é uma avaliação mais aprofundada de quais variáveis podem se relacionar com o interlock entre empresas, de modo a construir um modelo que aborde as diferentes relações empresariais e gerenciais passíveis de afetar a constituição do capital intelectual.

\section{AGRADECIMENTOS}

Trabalho desenvolvido com recursos da Fundação Araucária de Apoio ao Desenvolvimento Científico e Tecnológico do Estado do Paraná.

\section{REFERÊNCIAS}

ADAMS, R. B.; HERMALIN, B. E.; WEISBACH, M. S. The role of boards of directors in corporate governance: A conceptual framework and survey. Journal of economic literature, v. 48, n. 1, p. 58-107, 2010. DOI: 10.1257/jel.48.1.58

AL-MUSALI, M. A. K.; ISMAIL, K. I. Corporate governance, bank specific characteristics, banking industry characteristics, and intellectual capital (IC) performance of banks in Arab Gulf Cooperation Council (GCC) countries. Asian Academy of Management Journal of Accounting and Finance, v. 3, p. 115-135, 2012. Disponível em: http://web.usm.my/journal/aamjaf/vol\%208-s1-2012/8-s1-6.pdf. Acesso em: 02 mar. 2020.

ALVES, P.; COUTO, E. B.; FRANCISCO, P. M. Board of directors' composition and capital structure. Research in International Business and Finance, v. 35, p. 1-32, 2015. DOI: https://doi.org/10.1016/j.ribaf.2015.03.005. 
ANDRADE, L. P.; SALAZAR, G. T.; CALEGÁRIO, C. L. L.; SILVA, S. S. Governança corporativa: uma análise da relação do conselho de administração como valor de mercado e desempenho das empresas brasileiras. Revista de Administração Mackenzie, São Paulo, v. 10, n. 4, p. 4-31. 2009. DOI: http://dx.doi.org/10.1590/S1678-69712009000400002.

BEREZINETS, I.; GARANINA, T.; ILINA, Y. Intellectual capital of a board of directors and its elements: introduction to the concepts. Journal of Intellectual Capital, v. 17, n. 4, p. 632653, 2016. DOI: https://doi.org/10.1108/JIC-01-2016-0003.

BLANCO-ALCÁNTARA, D.; DÍEZ-ESTEBAN, J. M.; ROMERO-MERINO, M. E. Board networks as a source of intellectual capital for companies. Management Decision, v. 57, n. 10, p. 26532671, 2019. DOI: https://doi.org/10.1108/MD-12-2017-1238.

BONTIS, N. Intellectual capital: an exploratory study that develops measures and models. Management Decision, v. 36, n. 2, p. 63-76, 1998. DOI: https://doi.org/10.1108/00251749810204142.

BRANDT, V. A.; KOCHEN, R. M. Relação entre rentabilidade e capital intelectual de empresas do setor bancário brasileiro. Anais do Congresso Internacional de Conhecimento e Inovação - ciki, v. 1, n. 1, 2018. Disponível em:

https://proceeding.ciki.ufsc.br/index.php/ciki/article/view/575. Acesso em: 01 abr. 2020.

CHEN, H. L.; HO, M. H. C.; HSU, W. T. Does board social capital influence chief executive officers' investment decisions in research and development? R\&D Management, v. 43, n. 4, p. 381-393, 2013. DOI: https://doi.org/10.1111/radm.12025.

CHEN, X.; CHENG, Q.; WANG, X. Does increased board independence reduce earnings management? Evidence from recent regulatory reforms. Review of Accounting Studies, v. 20, n. 2, p. 899-933, 2015. DOI: https://doi.org/10.1007/s11142-015-9316-0.

CHU, J. S. G.; DAVIS, G. F. Who killed the inner circle? The decline of the American corporate interlock network. American Journal of Sociology, v. 122, n. 3, p. 714-754, 2016. DOI: 10.1086\%2F688650.

DAL VESCO, D. G.; BEUREN, I. M. Do the board of directors composition and the board interlocking influence on performance? BAR-Brazilian Administration Review, Rio de Janeiro, v. 13, n. 2, p. 1-26, 2016. DOI: http://dx.doi.org/10.1590/1807-7692bar2016160007.

DANI, A. C.; SANTOS, C. A.; KAVESKI, I. D. S.; CUNHA, P. R. Características do conselho de administração e o desempenho empresarial das empresas listadas no novo mercado. Revista de Gestão, Finanças e Contabilidade, v. 7, n. 1, p. 29-47, 2017. DOI: 10.18028/22385320/rgfc.v7n1p29-47.

DUCHIN, R.; MATSUSAKA, J. G.; OZBAS, O. When are outside directors effective? Journal of financial economics, v. 96, n. 2, p. 195-214, 2010. DOI: https://doi.org/10.1016/j.jfineco.2009.12.004. 
DŽENOPOLJAC, V.; JANOŠEVIC, S.; BONTIS, N. Intellectual capital and financial performance in the Serbian ICT industry. Journal of Intellectual Capital, v. 17, n. 2, p. 373-396, 2016. DOI: https://doi.org/10.1108/JIC-07-2015-0068.

EDVINSSON, L.; MALONE, M. S. Capital intelectual: descobrindo o valor real de sua empresa pela identificação de seus valores internos. São Paulo: Makron Books, 1998.

FORES, T. P. A influência do board interlock no desempenho das fusões e aquisições no Brasil. 2013. Dissertação (Mestrado Profissional em Administração) - Instituto de Ensino e Pesquisa (INSPER): São Paulo, 2013.

GALASKIEWICZ, J. WASSERMAN, S.; RAUSCHENBACH, B.; BIELEFELD, W.; MULLANEY, P. The influence of corporate power, social status, and market position on corporate interlocks in a regional network. Social Forces, v. 64, n. 2, p. 403-431, 1985. DOI:

https://doi.org/10.1093/sf/64.2.403.

GULATI, R.; WESTPHAL, J. D. Cooperative or controlling? The effects of CEO-board relations and the content of interlocks on the formation of joint ventures. Administrative science quarterly, v. 44, n. 3, p. 473-506, 1999. DOI: https://doi.org/10.2307/2666959.

KLEIN, A. Audit committee, board of director characteristics, and earnings management. Journal of accounting and economics, v. 33, n. 3, p. 375-400, 2002. DOI: https://doi.org/10.1016/S0165-4101(02)00059-9.

LAZZARINI, S. G. Mudar tudo para não mudar nada: análise da dinâmica de redes de proprietários no Brasil como "mundos pequenos". RAE eletrônica, v. 6, n. 1, p. 1-24, 2007. DOI: https://doi.org/10.1590/S1676-56482007000100007.

LEAL, R. P. C.; DE OLIVEIRA, C. L. T. An evaluation of board practices in Brazil. Corporate Governance: The international journal of business in society, 2002. DOI: https://doi.org/10.1108/14720700210440053.

LIMA, A. C.; CARMONA, C. U. Determinantes de la formación del capi tal in telectual en las empresas productoras de tecnología de la información y comunicación. RAM. Revista de Administração Mackenzie, v. 12, n. 1, p. 112-138, 2011. DOI: http://dx.doi.org/10.1590/S1678-69712011000100005.

LIU, C. H. The relationships among intellectual capital, social capital, and performance-The moderating role of business ties and environmental uncertainty. Tourism Management, v. 61, p. 553-561, 2017. DOI: https://doi.org/10.1016/j.tourman.2017.03.017.

MOURA, G. D.; FRANZ, L.; CUNHA, P. R. Qualidade da informação contábil em empresas familiares: influência dos níveis diferenciados de governança da BM\&FBovespa, tamanho e independência do conselho de administração. Contaduría y administración, v. 60, n. 2, p. 423-446, 2015. DOI: https://doi.org/10.1016/S0186-1042(15)30008-5. 
MOURA, G. D.; BEUREN, I. M. Conselho de administração das empresas de governança corporativa listadas na BM\&FBovespa: análise à luz da entropia da informação da atuação independente. Ciencias da Administraçao, v. 13, n. 29, p. 11-37, 2011. DOI: 10.5007/21758077.2011v13n29p11.

NKUNDABANYANGA, S. K. Board governance, intellectual capital and firm performance. Journal of Economic and Administrative Sciences, 2016. DOI: https://doi.org/10.1108/JEAS09-2014-0020.

OLIVEIRA, A. T. A., LUCENA, W. G. L., DE LIMA PEREIRA, M., \& DE BARROS CAMARA, R. P. Governança corporativa: um estudo da relação entre custo de agência e conselho de administração nas empresas listadas no IBrX-100. In: Congresso Brasileiro de Custos. Anais eletrônicos. Porto de Galinhas: CBC. 2016. Disponível em: https://anaiscbc.emnuvens.com.br/anais/article/view/4085. Acesso em: 01 abr. 2020.

OLIVEIRA, J. M.; BEUREN, I. M. O tratamento contábil do capital intelectual em empresas com valor de mercado superior ao valor contábil. Revista Contabilidade \& Finanças, v. 14, n. 32, p. 81-98, 2003. DOI: https://doi.org/10.1590/S1519-70772003000200006.

OZKAN, N.; CAKAN, S.; KAYACAN, M. Intellectual capital and financial performance: A study of the Turkish Banking Sector. Borsa Istanbul Review, v. 17, n. 3, p. 190-198, 2017. DOI: https://doi.org/10.1016/j.bir.2016.03.001.

PULIC, A. Measuring the performance of intellectual potential in knowledge economy. In: Annual National Business Conference. 19, 1998. Anais Eletrônicos, Ontário: McMaster University. Disponível em: https://www.bib.irb.hr/35384?rad=35384. Acesso em: 03 abr. 2020.

RAMADAN, B. M.; DAHIYAT, S. E.; BONTIS, N.; AL-DALAHMEH, M. A. Intellectual capital, knowledge management and social capital within the ICT sector in Jordan. Journal of Intellectual Capital, v. 18, n. 2, p. 437-462, 2017. DOI: https://doi.org/10.1108/JIC-06-20160067.

ROCHA, I.; PEREIRA, A. M.; BEZERRA, F. A.; DO NASCIMENTO, S. Análise da produção científica sobre teoria da agência e assimetria da informação. REGE-Revista de Gestão, v. 19, n. 2, p. 329-341, 2012. DOI: https://doi.org/10.5700/rege466.

ROSSONI, L.; MACHADO-DA-SILVA, C. L. Legitimidade, governança corporativa e desempenho: análise das empresas da BM\&F Bovespa. Revista de Administração de Empresas, v. 53, n. 3, p. 272-289, 2013. DOI: http://dx.doi.org/10.1590/S003475902013000300005.

ROSSONI, L.; ARANHA, C. E.; MENDES-DA-SILVA, W. Does the capital of social capital matter? Relational resources of the board and the performance of Brazilian companies. Journal of Management \& Governance, v. 22, n. 1, p. 153-185, 2018. DOI: https://doi.org/10.1007/s10997-017-9382-8. 
SHROPSHIRE, C. The role of the interlocking director and board receptivity in the diffusion of practices. Academy of Management Review, v. 35, n. 2, p. 246-264, 2010. DOI: https://doi.org/10.5465/amr.35.2.zok246.

SUBRAMANIAM, M.; YOUNDT, M. A. The influence of intellectual capital on the types of innovative capabilities. Academy of Management journal, v. 48, n. 3, p. 450-463, 2005. DOI: https://doi.org/10.5465/amj.2005.17407911.

TALIYANG, S. M.; JUSOP, M. Intellectual capital disclosure and corporate governance structure: evidence in Malaysia. International Journal of Business and Management, v. 6, n. 12, p. 109, 2011. DOI: http://dx.doi.org/10.5539/ijbm.v6n12p109.

TERJESEN, S.; COUTO, E. B.; FRANCISCO, P. M. Does the presence of independent and female directors impact firm performance? A multi-country study of board diversity. Journal of Management \& Governance, v. 20, n. 3, p. 447-483, 2016. DOI:

https://doi.org/10.1007/s10997-014-9307-8.

VALADARES, S. M.; LEAL, R. P. C. Ownership and control structure of Brazilian companies. Revista ABANTE, v. 3, n. 1, p. 29-56, 2000. DOI: http://dx.doi.org/10.2139/ssrn.213409.

YOUNDT, M. A.; SNELL, S. A. Human resource configurations, intellectual capital, and organizational performance. Journal of managerial issues, p. 337-360, 2004. Disponível em: https://www.jstor.org/stable/40604485. Acesso em: 01 maio 2020.

ZAHRA, S. A.; PEARCE, J. A. Boards of directors and corporate financial performance: A review and integrative model. Journal of management, v. 15, n. 2, p. 291-334, 1989. DOI: https://doi.org/10.1177/014920638901500208. 